\title{
Performance of a new hybrid cutting-abrasive tool for the machining of fibre reinforced polymer composites
}

\author{
Islam Shyha ${ }^{1,2}$ (D) $\cdot$ Dehong Huo $^{3} \cdot$ Peyman Hesamikojidi $^{3} \cdot$ Hossam Eldessouky $^{4} \cdot$ Mahmoud Ahmed El-Sayed $^{4}$
}

Received: 18 June 2020 / Accepted: 7 December 2020 / Published online: 22 December 2020

(C) The Author(s) 2020

\begin{abstract}
A new hybrid cutting-abrasive machining tool (turn-grind) is detailed for high-quality machining of fibre reinforced polymer (FRP) composites, comprising single point carbide inserts electroplated with multi-layers of diamond abrasives $120 \mu \mathrm{m}$ grain size, to form an abrasive region adjacent to an abrasive-free cutting edge. Experimental data are presented for turning tubes of CFRP and GFRP. The surface quality of workpieces after machining was evaluated through surface roughness measurements and SEM imaging. Cutting-only caused more defects such as delamination and fibre to pull out. Compared with cutting-only, contact and non-contact measurement of surface roughness (Ra) in both axial and radial directions showed an increase for CFRP and GFRP with roundness error reduced to 50\%. No significant increase in cutting force was observed.
\end{abstract}

Keywords CFRP · GFRP · Composite machining · Hybrid machining · Abrasive machining

\section{Introduction}

The use of composite materials is rapidly increasing due to their superior mechanical properties, in particular, the strength to weight ratio. Typically, a single machining process is applied to achieve the required dimensional accuracy and geometrical requirement of composite components. Previous research was widely conducted to understand machining characteristics of different types of composite materials either experimentally $[1,2]$ or numerically $[3-5]$. However, with the emergence of carbon and glass fibre reinforced polymers (CFRP and GFRP) as possible alternatives for metals, industries such as aerospace and automotive have set stringent

Islam Shyha

i.shyha@napier.ac.uk

1 Mechanical and Construction Engineering Department, Northumbria University at Newcastle, Newcastle upon Tyne NE1 8ST, UK

2 School of Engineering and the Built Environment, Edinburgh Napier University, Edinburgh EH10 5DT, UK

3 Mechanical Engineering, School of Engineering, Newcastle University, Newcastle upon Tyne NE1 7RU, UK

4 Department of Industrial and Management Engineering, Arab Academy for Science and Technology and Maritime Transport, Abu Qir, PO Box 1029, Alexandria 21599, Egypt requirements on surface integrity and accuracy of machined parts. Hybrid machining has the potential to fulfil these requirements. Hybrid manufacturing processes are based on the simultaneous and controlled interaction of process mechanisms and energy sources/tools. Lauwers et al. [6] have reported the significant effect when hybrid processes are used on the process performance due to the combined actions of the processes which result in higher machinability, reduction in processes forces and tool wear. Hybrid processes exploit the advantages of one process and overcome the limitation of others. Hybrid processes can have positive effects on component surface integrity as well as minimizing production time.

Combining multiple manufacturing operations into one was the title of many earlier studies. Li et al. [7] have proposed an Electrical Discharge Machining EDM-end milling model, in which non-traditional machining (EDM) was combined with traditional machining (Milling). The endmill has been used as a cutting tool when the cutting edges contact the workpiece and act as an electrode when there is no contact between the tool and workpiece. Their results showed a significant improvement in the surface roughness of machined components as well as tool wear. However, the surface quality worsened when high energy pulse was used. The ultrasonicassisted turning was another example of the hybrid processes being used to improve surface quality $[8,9]$, in which a piezoelectric transducer device was attached to the cutting tool to generate a controlled vibration whilst maintaining enough 
stiffness to cut the material without deflection. This hybrid technique was found to have a beneficial effect on enhancing the surface finish for different materials such as mild steel and SiC-reinforced aluminium matrix composites. Rotary ultrasonic machining is another hybrid machining process that combines the ultrasonic machining and grinding was also studied by Ning and co-authors [10]. In this study, the hybrid process was used to create holes in a CFRP. The authors reported a considerable reduction in the cutting force, torque and as well as the surface roughness associated with the use of the hybrid technique.

Although fibre reinforced plastic components are made to near net-shapes, machining is required to achieve final dimensional and geometrical accuracy of the product in addition to fulfil assembly requirements. A hybrid machining system (cutting and abrasive machining) could be used to maintain a high material removal rate as well as produce low surface roughness. To date, hybrid processes involving grinding relevant for FRP machining are limited to non-conventional operations such as abrasive electro discharge grinding and abrasive, electrochemical machining. Hu and Zhang [11] observed that delamination experimentally, fibre pull-out and burn can typically occur when grinding of CFRPs, using alumina grinding wheels, due to their inhomogeneity. Carbide tools are not capable of lasting very long when machining carbon and glass fibres due to their highly abrasive properties, Quan and Zhong [12] evaluated the use of different tool arrangement including plated diamond core drill, cemented diamond core drill, plated solid drill for hole making in CFRP plates aiming to improve tool life and surface quality. Regardless of the tool type, the study recommended the use of shallow feed rate of $0.01 \mathrm{~mm} /$ rev, which would have a knock-on effect on productivity.

Grinding and abrasive machining are similar, with the main difference being the process parameters that they adopt. They have been popular amongst researchers for machining FRPs as they can improve surface finish and tool life by dividing machining forces over many cutting edges and achieving high specific cutting energy. Soo et al. [13] have investigated the effect of high-speed routing of CFRP laminates using singlelayer electroplated diamond and CBN grinding points as opposed to standard end milling tools. They found that small diamond grains ( $76 \mu \mathrm{m}$ grit size) improved surface roughness to below $3 \mu \mathrm{m}$ Ra as a result of reducing the size of feed marks. Boudelier et al. [14] have employed diamond abrasives grinding points with grit size range from 427 to $1182 \mu \mathrm{m}$ for trimming $9.1 \mathrm{~mm}$ thick CFRP plates. Surface roughness was assessed, and a high correlation between the abrasive size and roughness values was reported. The lowest Sa of $20 \mu \mathrm{m}$ was obtained when the smallest diamond abrasives were used whilst when $1182 \mu \mathrm{m}$ grit size was used, Sa values reached threefolds.

A significant concern for grinding tools is the clogging of spaces between abrasive grains by the chips, which can impair the grinding process and cause burning and other defects in the workpiece. Quan and Zhong [12] have also found that compared with the cemented diamond core drills, the plated diamond tools were not easily clogged or smeared out which is believed to be due to their self-dressing capability in addition to the larger chip pockets between particles.

Due to the advanced technology required in various engineering applications such as aerospace, the demand for materials having high strength and low weight is increasing. Therefore, this study offers insight into machining composite materials. In addition, earlier research has already investigated the high accuracy machining of metals. However, composite machining with high accuracy still imposes limitations. Therefore, this paper proposes a new hybrid cutting-abrasive tool. Tool design and initial results when the developed tools were used on machining of CFRP and GFRP composites are presented.

\section{Experimental work}

The cutting-grinding tools were fabricated from tungsten carbide turning inserts (CNMA120408THM-K30). The tool body comprised both the main cutting edge and a secondary grinding region (separated by a $0.5-2.0-\mathrm{mm}$ gap), which initially acts in sequence and then simultaneously on the material surface. All inserts were wire EDM-ed to create a groove (see Fig. 1a), which was subsequently electroplated to provide a grinding region (see Fig. 1b). Only the groove was multi-layer electroplated (Ni bond) with $120 \mu \mathrm{m}$ diamond superabrasives; see Fig. 2. This created a gradual grinding process with a maximum grinding depth on the new tools of $\sim 100 \mu \mathrm{m}$. Figure 3 illustrates the schematic of the hybrid process where the depth of cuts for cutting and grinding are indicated.

To evaluate the performance of the hybrid cutting tool during the machining of composite materials currently used in industry, two different composite types were included in the current work namely carbon fibre reinforced plastic and glass fibre reinforced plastic (CFRP and GFRP). In this study, CFRP and GFRP tubes of 55/66 mm ID/OD and $130 \mathrm{~mm}$ long were made up of epoxy resin-based plies pre-impregnated (prepreg) with woven fibre. Carbon $280 \mathrm{~g} / \mathrm{m}^{2} 4 \times 4$ twill and E-glass $202 \mathrm{~g} / \mathrm{m}^{2}$ plain weave were used to make the CFRP and GFRP tubes with fibre volume fractions of $45 \%$ and $42 \%$, respectively. Turning/grinding experiments were performed on a Hurco TM10 CNC lathe with a maximum spindle speed of $3500 \mathrm{rpm}$ rated at $3 \mathrm{~kW}$. Workpiece tubes were held in a 3jaw chuck, and tools were controlled using a bespoke adaptor mounted on a Kistler 9129AA, 3-component force dynamometer, as shown in Fig. 4. Signals were processed using a multichannel charge amplifier 5070A and a data acquisition system 5697A1, which were connected to a PC installed with force signal recording and manipulation software (Dynoware). Despite some benefits for using coolant reported in the 
Fig. 1 a Cutting tool insert with a wire EMD-ed groove. b Hybrid cutting tool with electroplated abrasive zone

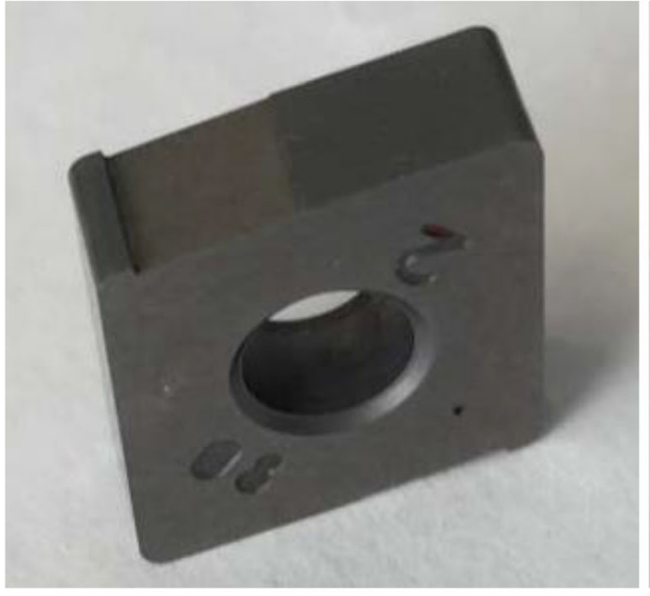

(a)

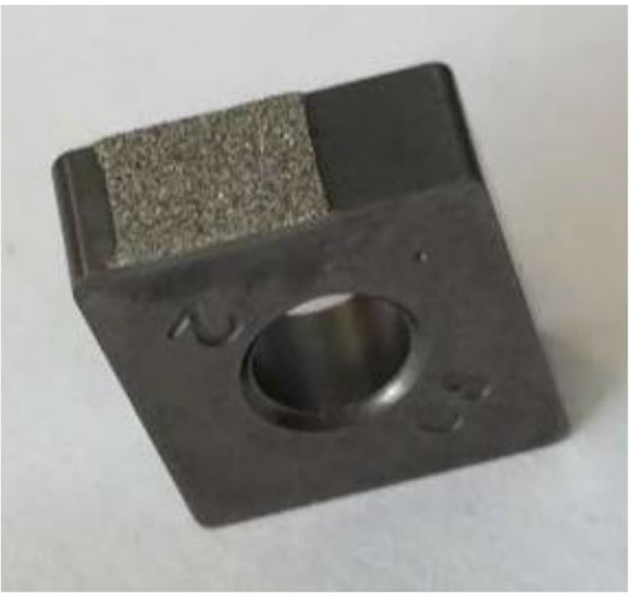

(b) literature, dry machining is recommended by industries for economic and environmental reasons. Therefore, dry cutting was employed in this work.

The two experimental phases in this research were conducted using the same conditions, but the first employed standard carbide tools whilst the second phase was carried out using the new hybrid cutting-abrasive tools. Each phase included 18 trials on CFRP tubes. Experiments involved cutting speeds of 207, 310 and $414 \mathrm{~m} / \mathrm{min}$; feed rates of $0.1,0.15$ and $0.2 \mathrm{~mm} / \mathrm{rev}$; and depths of cut of 0.25 and $0.5 \mathrm{~mm}$. Two

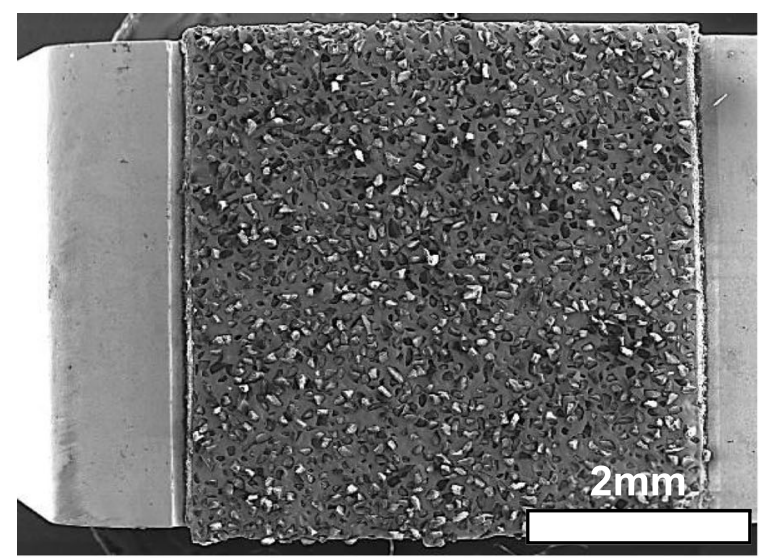

(a)

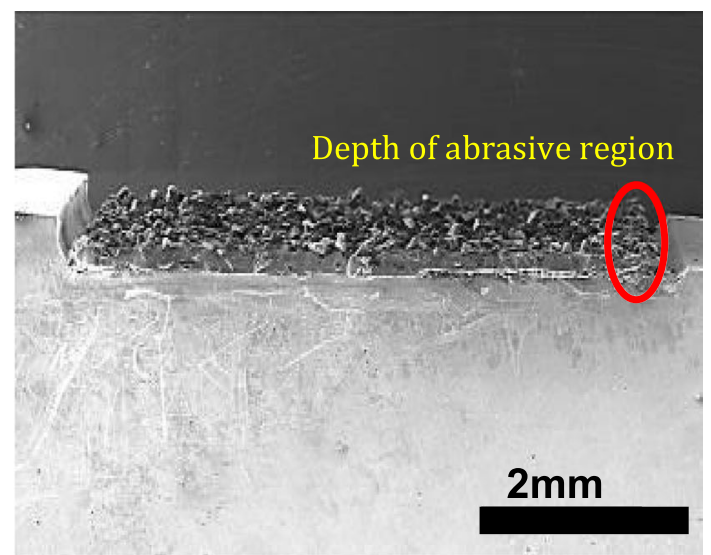

(b)

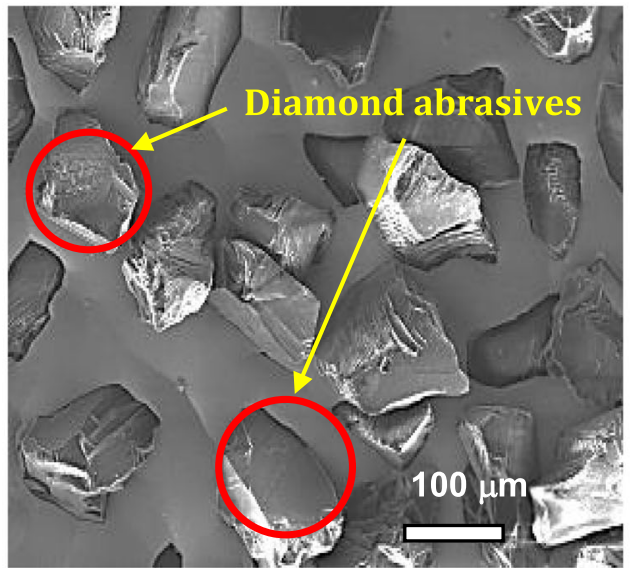

(c)

Fig. 2 SEM images of a top view of the hybrid cutting tool, $\mathbf{b}$ cross-section of abrasive tool strip and $\mathbf{c}$ abrasive particles before machining is performed 
Fig. 3 Schematic diagram of the hybrid process
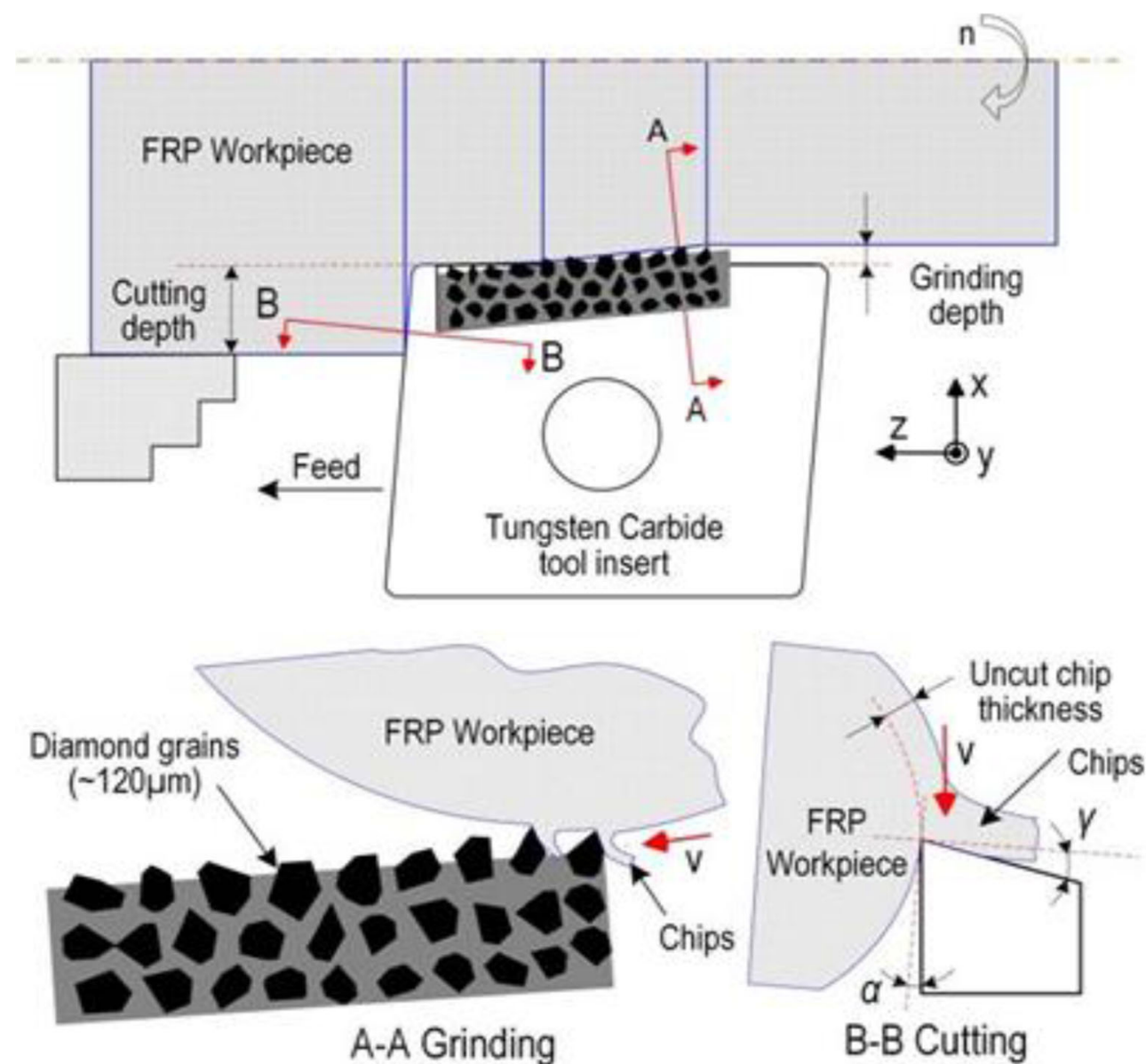

B-B Cutting more trials on GFRP tubes were added for benchmarking (at two cutting speeds of 207 and $414 \mathrm{~m} / \mathrm{min}$ and constant feed rate and depth of cut of $0.1 \mathrm{~mm} / \mathrm{rev}$ and $0.25 \mathrm{~mm}$, respectively). Cutting speed levels were carefully selected to provide a compromise between typical levels of turning and grinding, hence the relatively low maximum grinding speed of $6.9 \mathrm{~m} / \mathrm{s}$. Samples were randomly machined to reduce the chance of systematic errors. A constant machining length of $70 \mathrm{~mm}$ was used for all trials.

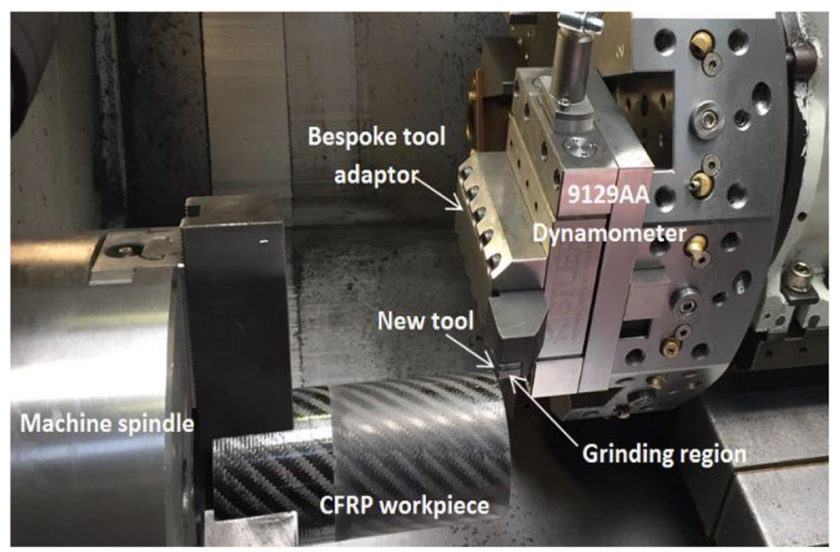

Fig. 4 Experimental setup
A scanning electron microscope (SEM) was employed to characterize the condition of the tools, chip morphology, damage and machining patterns on the tubes. Non-contact measurement of surface roughness $(\mathrm{Ra})$ in the axial and radial directions was performed using a 3D surface profilometer, Alicona InfiniteFocus G4. Surface roughness was also evaluated using a contact stylus profilometer $(0.8 \mathrm{~mm}$ cut-off, $4 \mathrm{~mm}$ and $2 \mathrm{~mm}$ evaluation length in axial and radial directions, respectively). An Impact $600 \mathrm{CMM}$ equipped with a Renishaw probe was employed to assess dimensional accuracy and roundness error of the machined tubes.

Chips were collected for all samples for analysis. A selection of post-machining tests was performed on the workpieces to evaluate the performance of hybrid tools in comparison with the single point carbide insert. The scanning electron microscope was employed to characterize the condition of the tools, chip morphology, damage and machining patterns on the tubes. Raw profile data were also collected from the scans, which were then used to process spatial frequency via fast Fourier transform (FFT). This mathematical tool can be used to extract dominant frequencies within a noisy signal. It is mostly used for data in the time domain; however, it can also be used to determine dominant frequencies within spatial data. 
An XPS analysis was performed on a Thermo K-Alpha XPS spectrometer to investigate the effect of heat on the cutting-abrasion machined surface. Two small squares corresponding to un-machined and cutting-grinding machined surfaces were cut from two workpieces (one from CFRP and one from GFRP) for the analysis; this was carried out to use the un-machined surface as a benchmark for melting of the epoxy during machining. The samples were mounted on a clean stainless steel plate using carbon adhesive tape. All measurements were repeated at three positions on each sample with non-overlapping analysis areas. The largest analysis area (nominally $400 \mu \mathrm{m}$ diameter) was used in all measurements. ANOVA was chosen as the main statistical tool for evaluating the data resulting from the analysis methods described above, Sigmaplot software was used to run ANOVA on cutting forces, surface roughness and roundness error data to determine the significance of different parameters' effects on the outcomes.

\section{Results and discussion}

\subsection{Geometrical accuracy}

Compared with cutting-only, roundness error was improved by the cutting-abrasion process in $89 \%$ of the samples with an average improvement of roughly two times; see Fig. 5. The roundness error of both cutting-only and cutting-abrasion peaked at $310 \mathrm{~m} / \mathrm{min}$, above and below which, they were level. The highest accuracy for abrasive machining was achieved at $210 \mathrm{~m} / \mathrm{min}$ with a form error of around $0.03 \mathrm{~mm}$. For cutting, the error was $0.059 \mathrm{~mm}$ at $414 \mathrm{~m} /$ min. It should be noted that the overlap between the cutting and abrasion operations associated with the use of the hybrid tool would affect its performance. Besides, the change of roundness error with the cutting speed for both cutting tools which could be caused by potential thermal effects on the carbide inserts. The effect of feed rate was such that both processes saw an initial rise in roundness error with feed rate increasing from 0.1 to $0.15 \mathrm{~mm} / \mathrm{rev}$; however, a further increase saw a reduction of error in the new tool to a minimum of $0.029 \mathrm{~mm}$, whilst cutting-only operation continued to rise to a maximum of $0.068 \mathrm{~mm}$. This is because increasing the feed rate in abrasive machining reduces the detrimental effect of tool stagnation and improves surface quality, whereas it is known to increase machining damage in cutting-only. Depth of cut had little effect on the form error of the cutting process as both levels showed an error of roughly $0.06 \mathrm{~mm}$. Abrasive machining, however, experienced improvement as the error nearly halved when the higher depth of cut was applied, which could be because more of the abrasive grains is engaged with the workpiece at deeper levels and result in a more uniform material removal mechanism. With these main effect results, it can be said that the optimal conditions for abrasive machining of FRP composites are at a cutting speed of $207 \mathrm{~m} / \mathrm{min}$, a feed rate of $0.2 \mathrm{~mm} / \mathrm{rev}$ and $0.5 \mathrm{~mm}$ depth of cut. Analysis of variance (ANOVA) was performed on the form error data to detect significant relationships between process variables and the level of form error. The resulting $P$ values of all parameters for the cutting-abrasion process were lower than 0.05 , therefore, rejecting the null hypothesis and signifying a relationship between varying process parameters and form error. On the other hand, parameters concerning the cutting operation did not show a significant difference; nevertheless, optimal parameters were identified through main effect graphs.

\subsection{Surface quality}

SEM examination of machined surfaces of the CFRP and GFRP tubes revealed variations in surface damage pattern, depending on the material and tools used. Flaws in terms of voids were apparent when conventional cutting inserts (abrasive free) were used. Whilst the new cutting-abrasive tools produced lower levels of damage (voids, cavities and fibre pull-out), but with more obvious tool feed marks; see Fig. 6 . The surface improvement was more remarkable on CFRP tubes as opposed to GFRP tubes, as shown in (b, d). On GFRP tubes, only feed marks and smaller areas of material residue were observed when hybrid machining compared with larger damage areas $(\sim 500 \mu \mathrm{m})$ when cutting only, see (c) and (d), respectively.

The fibre reinforcement characteristics play an essential role in the resulting surfaces. Carbon fibres are more difficult to machine as they have higher strength and stiffness compared to glass fibres, which has led to severe surface damage in the cutting-only zone. The coupled abrasive machining in the hybrid tool relieved these damages by dividing the cutting force over a high number of cutting edges (abrasive grains) and dividing the material removal process into small steps, evidenced by the powder form chips. It should be noted that machining of CFRP can result in oxidation and subsequent polymer decomposition. This would lead to the graphitisation of diamond grits and in turn, deterioration of the performance of the hybrid tool.

On the other hand, the glass fibres have lower strength and stiffness. However, a much higher strain to failure as confirmed by Sheikh-Ahmad [15] meaning that it is more prone to defects such as fibre pull-out and delamination caused by bending. Glass fibres have a lower thermal conductivity than carbon fibres; therefore, the effect of machining temperature is more significant in GFRP. In the proposed cutting-abrasion process, the leading cutting edge removes the bulk material, and the generated heat subsequently affects the abrasion process due to the softening or melting of the epoxy matrix. This effect could explain the adverse results seen in cuttingabrasion of the GFRP samples, considering that the 
Fig. 5 Main effect plots for roundness error

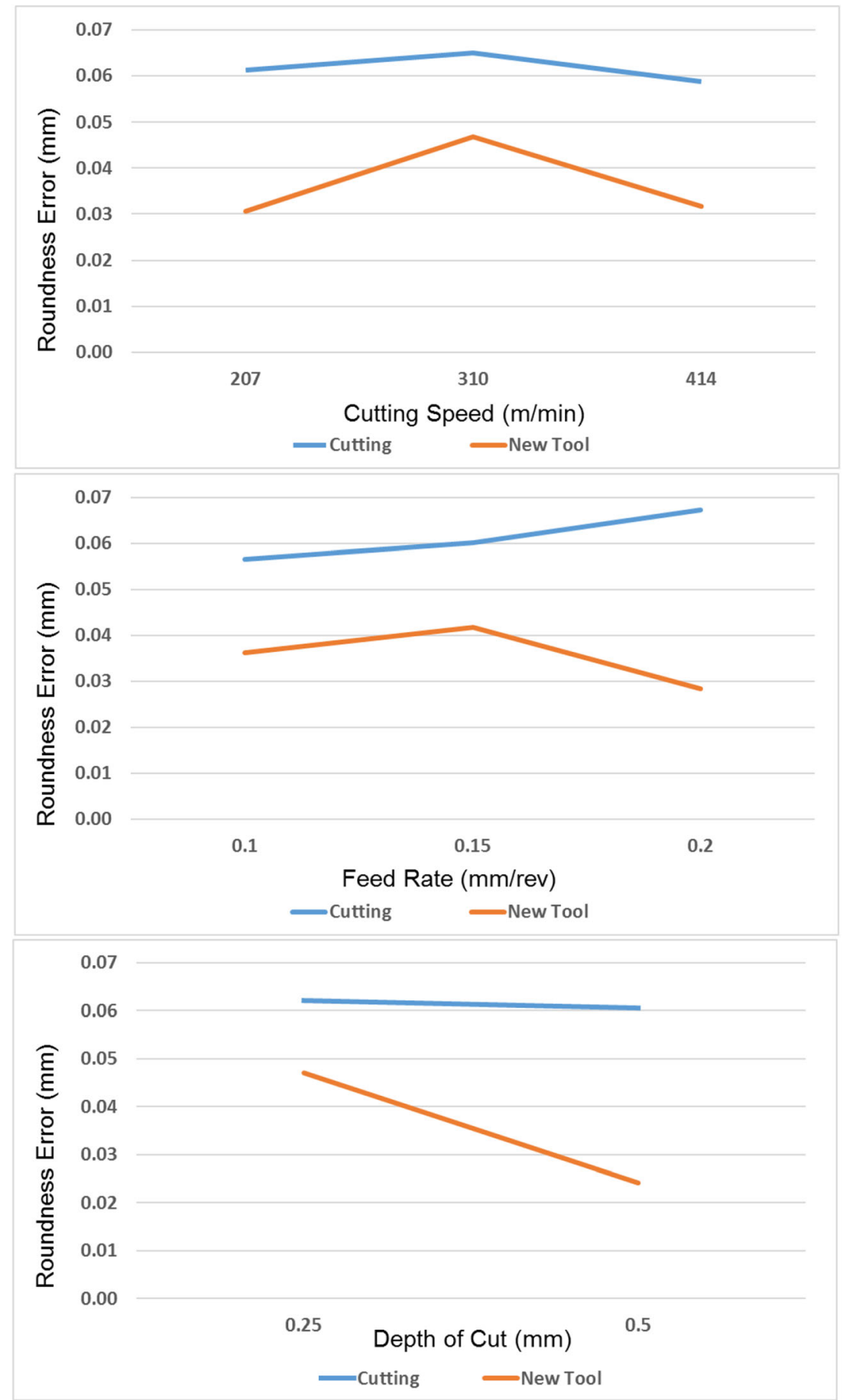

recommended cutting speed by Sheikh-Ahmad [15] for optimal machining temperature during turning for GFRP is 60 $150 \mathrm{~m} / \mathrm{min}$, depending on the cutting tool, and that a cutting speed of $200 \mathrm{~m} / \mathrm{min}$ was deployed for this sample. Softening the epoxy beyond the critical glass transition temperature means that it does not maintain enough support for the fibres. Therefore damages like delamination and fibre pull-out become widespread, as is the case in this sample.

\subsubsection{Surface roughness}

The results presented in Fig. 7 show the roughness of cuttingonly regions and those where cutting-abrasion was performed. It is clear that regardless of the levels of process parameters, cutting-abrasion roughness values are higher than cutting-only. The axial roughness values were lower than radial values for both sets of results. This is unusual for abrasive machining 


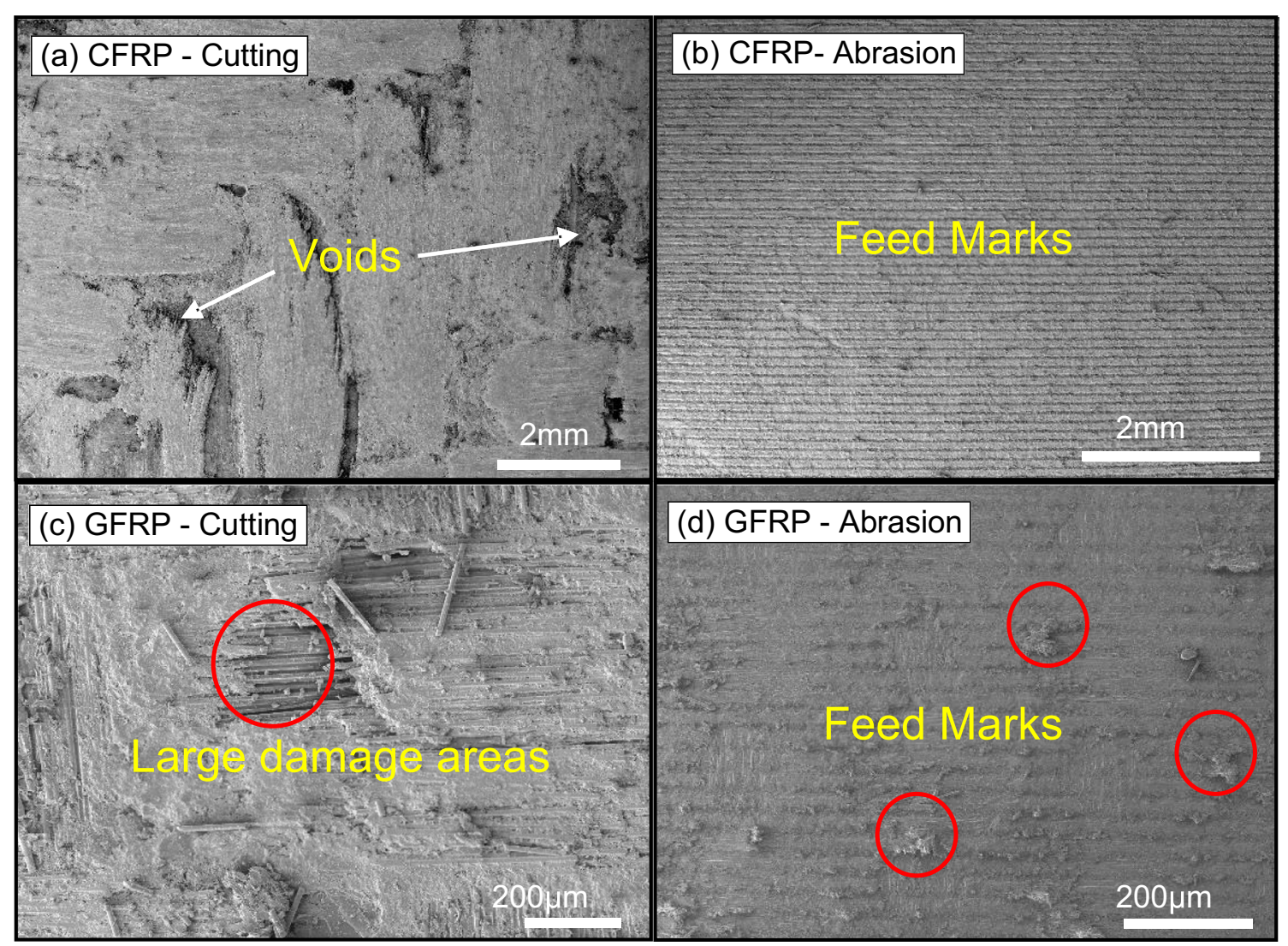

Fig. 6 SEM images of CFRP and GFRP samples at cutting-only and cutting-abrasion regions

because roughness measurements in the radial direction are not affected by feed marks and should therefore be lower. The reason for this could be the adhesion of chips within the trenches, causing the measured roughness values to increase.

Roughness increased with feed rate and vice versa for the abrasive machining. The reason is mainly due to the reduction of tool stagnation at higher feed rates. This is promising for the hybrid abrasive machining as higher feed rates are desirable for higher productivity. For cutting speed, there was a positive correlation where higher speeds resulted in higher roughness values. There was a slight decrease in the roughness of about $0.5 \mu \mathrm{m}$ when a depth of cut of $0.5 \mathrm{~mm}$ was used for the abrasive machining. However, plain cutting had an increase in roughness when the higher depth of cut was used. It is noticeable that the surface roughness associated with the use of the hybrid tool was marginally higher than that related to the use of the traditional tool. This might be due to the clogging of the diamond tips with the chip produced, which affect the abrasion process. This would require further investigation to understand this observation fully. For instance, the effect of abrasive grain size on the degree of clogging might be studied and accordingly such grain size might be optimized towards the elimination of the clogging aiming to enhance the surface finish of the machined composite parts.
Another reason that might detrimentally affect the surface quality is the cutting across the fibres that would increase the roughness in the radial direction. Finally, the expected rise in the temperature, as a result of dry machining, above the critical glass transition temperature might cause softening of the polymer matrix which harmfully affects the machining operation and contributes to the overall increase in the surface roughness.

It should be noted that abrasive machining turns into a grinding process only when higher cutting speeds are employed. Consequently, lower roughness values (better surface quality) have been reported for grinding of FRPs. This is indicated in the main effect graphs of abrasive machining showing form error, where the curve starts low, reaches a peak at the median cutting speed and feed rate and then drops for the highest settings. Further experiments at higher spindle speeds are deemed required to achieve full grinding range, which may result in a downward trend and a reduction in surface roughness. ANOVA was performed on the roughness data against the process parameters, and no significant relationship was detected.

Surface profile in terms of the dominant frequency along the surface was analysed to explain the surface roughness measurement further. As expected, the dominant frequency detected by FFT (see Fig. 8) for the cutting-abrasion profile is at $1 / 10 \mathrm{~mm}$, corresponding to the $0.1 \mathrm{~mm} / \mathrm{rev}$ feed rate, at 
Fig. 7 Main effect plots for surface roughness $(\mathrm{Ra})$

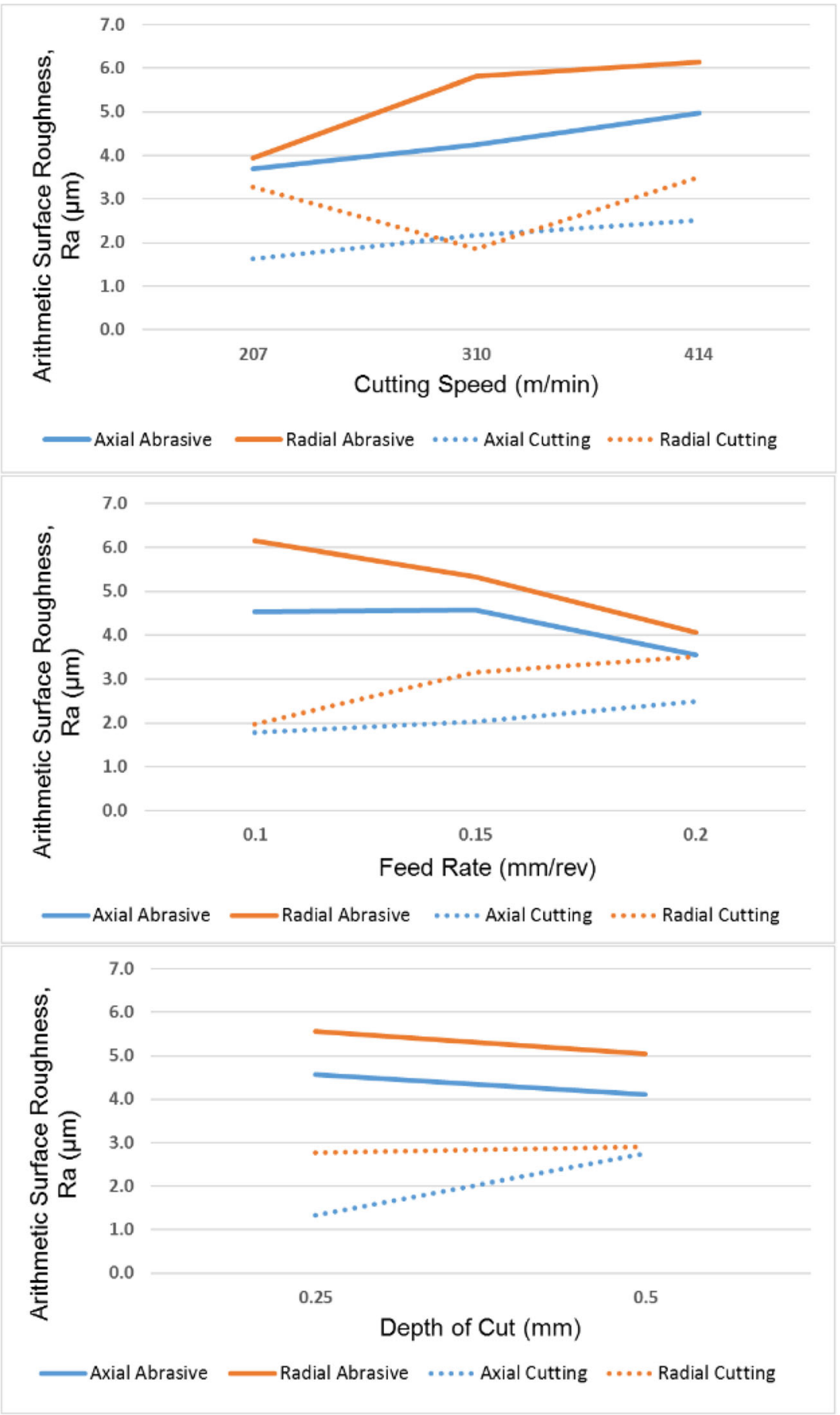

which the sample was machined. This proves that the most significant factor in creating the rough surface on the abrasive machined samples is feed marks. With reference to the main effect graph, it is apparent that the roughness is at its lowest when higher feed rates are used. This is due to the lower number of repeating patterns left by the tool at higher feed rates. Cutting-only, however, displayed a range of low amplitude peaks, none of which correspond to the feed rate, indicating that the peaks resemble the regular occurrence of defects such as delamination, which is shown in SEM images.

\subsubsection{XPS analysis}

The primary purpose of the XPS analysis was to find out if the epoxy matric had been melted during machining, hence hindering the surface quality by smearing and re-solidifying 
Fig. 8 Fast Fourier transform peaks of cutting and abrasion region surface profiles
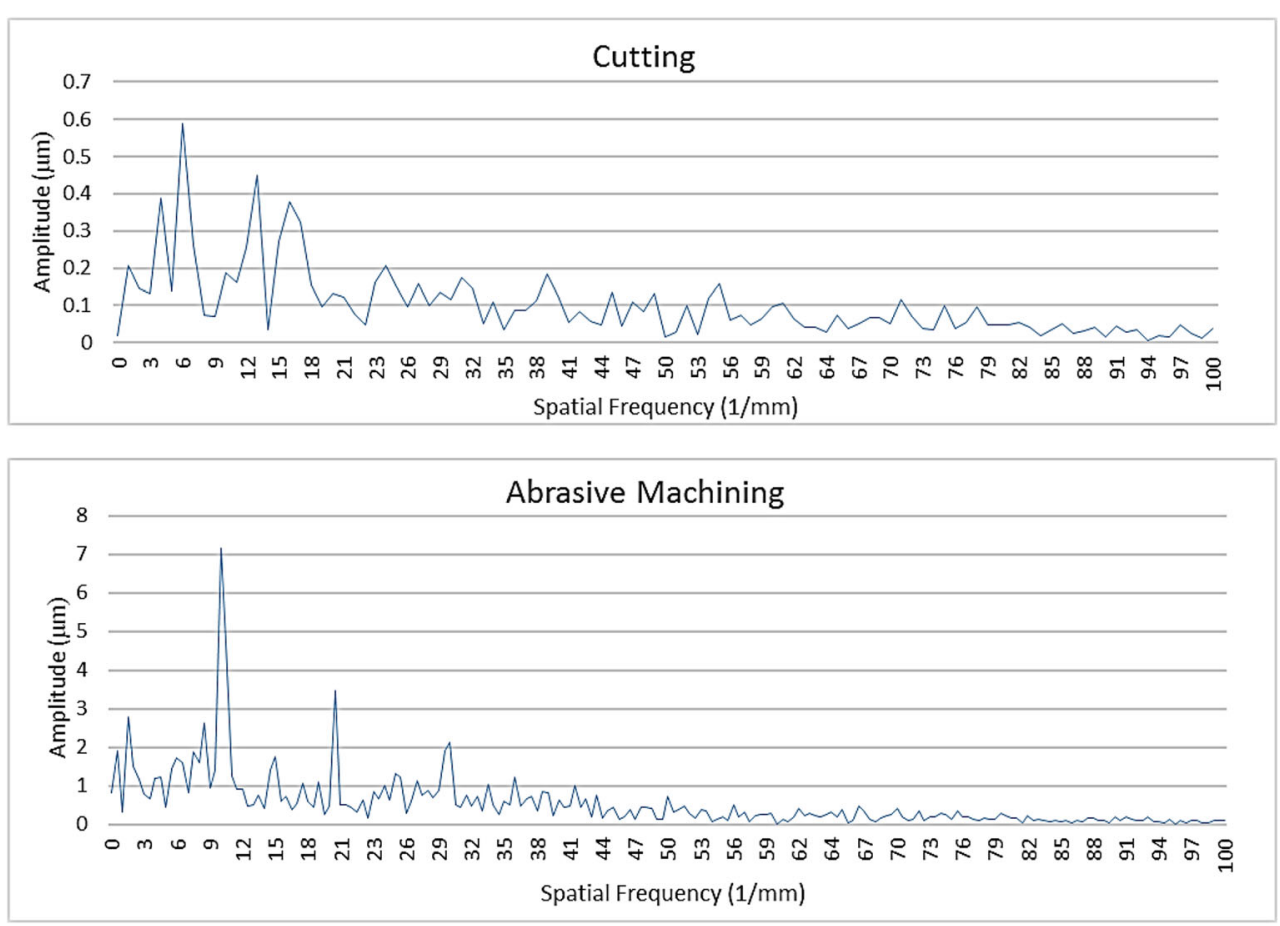

randomly on the surface (Fig. 9). The chemical state analysis targeted thermal degradation of epoxy. The elemental composition on the surface of the samples shows a general reduction in carbon $1 \mathrm{~s}$ and nitrogen $1 \mathrm{~s}$ and an increase in oxygen $1 \mathrm{~s}$ after machining for both materials.

The shift in carbon $1 \mathrm{~s}$, which is supposed to have a binding energy of $284.6 \mathrm{eV}$, was used to determine the shift in the functional groups present on the surface of the samples using Casa XPS software. Four function groups were identified and fitted into the $\mathrm{C} 1 \mathrm{~s}$ curves consisting of aliphatic carbon $(\mathrm{C}-\mathrm{C})$, alcohol and ether groups $(\mathrm{C}-\mathrm{OH}$ and $\mathrm{C}-\mathrm{O}-\mathrm{C})$, Ketone $(\mathrm{C}=\mathrm{O})$ and ethers and acids $(\mathrm{O}-\mathrm{C}=\mathrm{O})$. The percentage make up of each function group in all samples is presented in Table 1.

A reduction in the $\mathrm{C}-\mathrm{C}$ function group for both materials is in line with the findings by Awaja and Pigram [16] in a study of accelerated thermal degradation of epoxy as a result of polymer chain breakage. Oxidation is also proven through the rise of $\mathrm{C}-\mathrm{O}-\mathrm{C}$, and this has been the case for the thermal degradation of epoxy, which suggests that the heat generated from the cutting-abrasive machining process has indeed
Fig. 9 Machined GFRP surface showing epoxy smearing

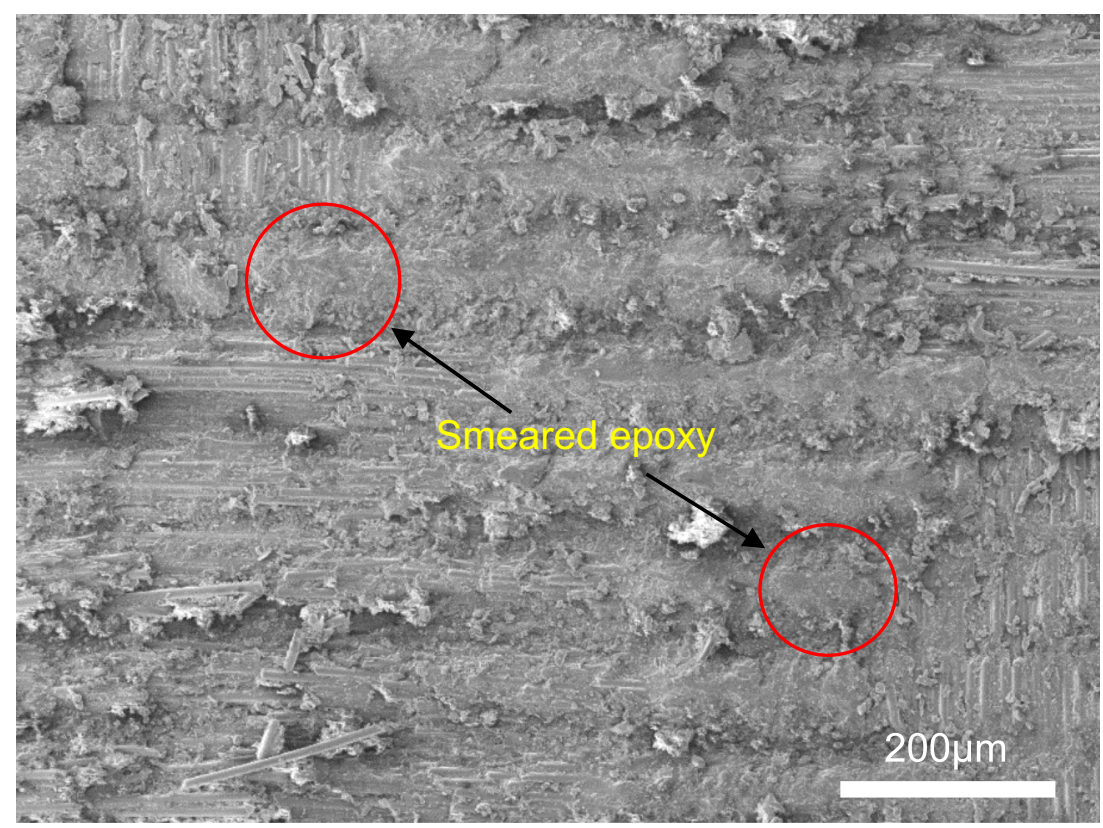


Table 1 Function group make up of samples before and after machining

\begin{tabular}{lllll}
\hline Sample & \multicolumn{4}{l}{ Function groups (\%) } \\
\cline { 2 - 5 } & C-C C-H & C-OH C-O-C & $\mathrm{C}=\mathrm{O}$ & $\begin{array}{l}\mathrm{O}- \\
\mathrm{C}=\mathrm{O}\end{array}$ \\
\hline CFRP (machined) & 82.02 & 13.84 & 1.14 & 3.00 \\
CFRP (un-machined) & 86.86 & 8.29 & 0.79 & 4.07 \\
GFRP (machined) & 74.30 & 21.27 & 1.51 & 2.93 \\
GFRP (un-machined) & 80.24 & 15.29 & 1.86 & 2.61 \\
\hline
\end{tabular}

resulted in thermal degradation and melting of the epoxy, which in effect has been a major cause of the rough surface of the hybrid machined surfaces. This is believed to be eliminated if the main tool is cooled using a suitable cutting fluid and so it will be tested in future studies.

\subsection{Post-machining tool examination}

The novel cutting-abrasive machining tools were designed and fabricated to ensure that a gap between the cutting edge and abrasive region was maintained to avoid abrasive loading. Despite the use of a new tool for each experiment, SEM examination of the cutting-abrasive tools following the machining of FRP revealed severe chip clogging between diamond abrasives; see Fig. 10a, b. This was attributed to the dry cutting condition, and it is anticipated that chip clogging would be reduced if flood cooling was used or by channelling designated chip flushing trenches. No obvious grain fracture or grit loss/pull-out was observed on any of the evaluated tools. Edge rounding on the diamond abrasives was the dominant wear mechanism; see Fig. 10c. This is not uncommon when machining CFRP using either a conventional cutting edge or abrasive grits and is attributed to the abrasive properties of carbon fibre reinforcement as observed by Ruszaj et al. [17]. Additionally, matrix resin melt and cut fibres were observed on abrasive surfaces; see Fig. 10d.

\subsection{Machining forces}

The use of the new cutting-abrasive tools resulted in a general reduction of the resultant force compared with conventional cutting. Figure 11 shows resultant force data vs cutting speed and feed rate for both types of tool. A more significant reduction was recorded in the radial force direction $(F x)$, although no significant increase in cutting force $(F y)$ was observed. Forces of hybrid machining increased with feed rate and depth of cut and decreased with cutting speed, which was in line
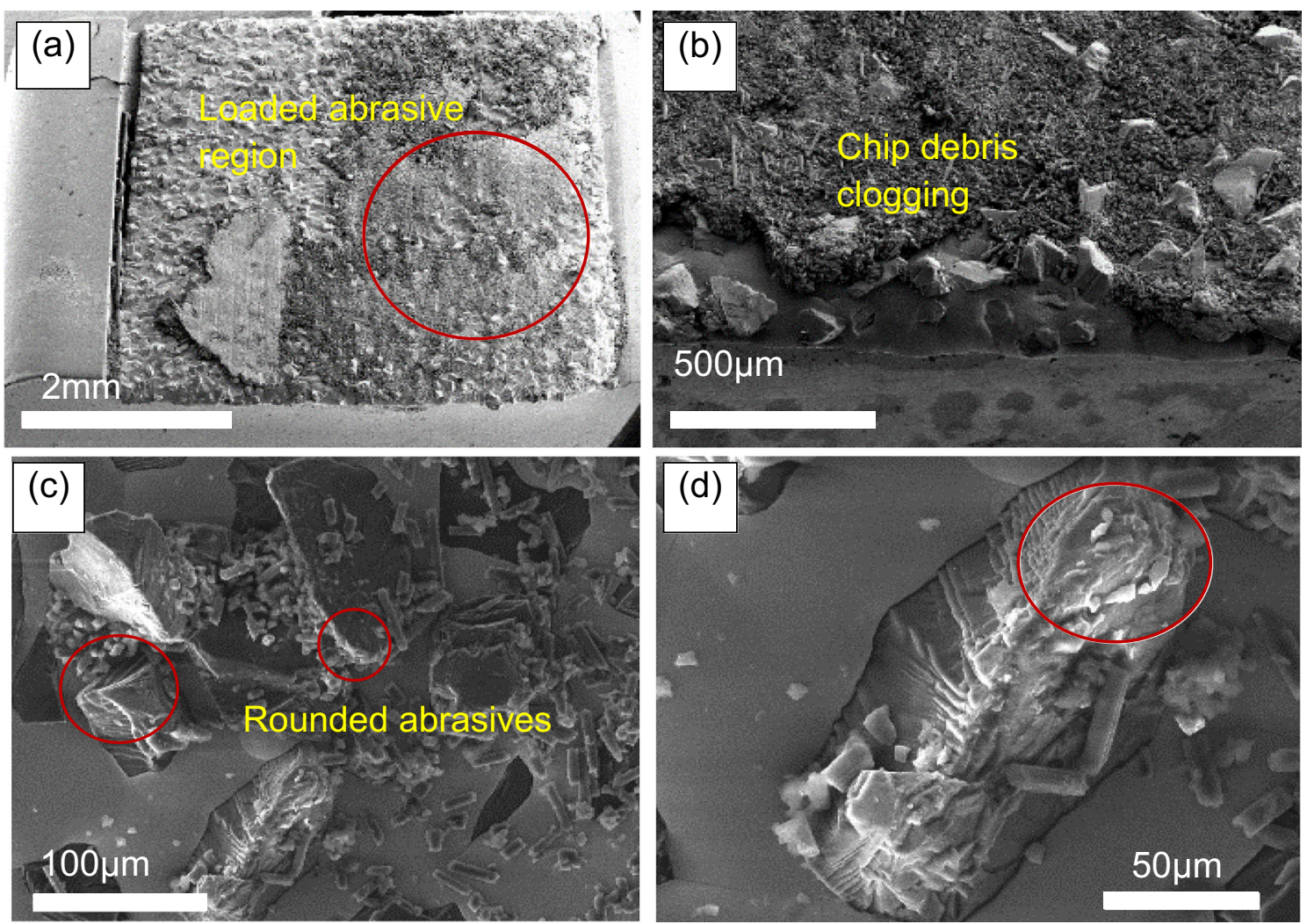

Fig. 10 SEM images of cutting tool after machining of CFRP 


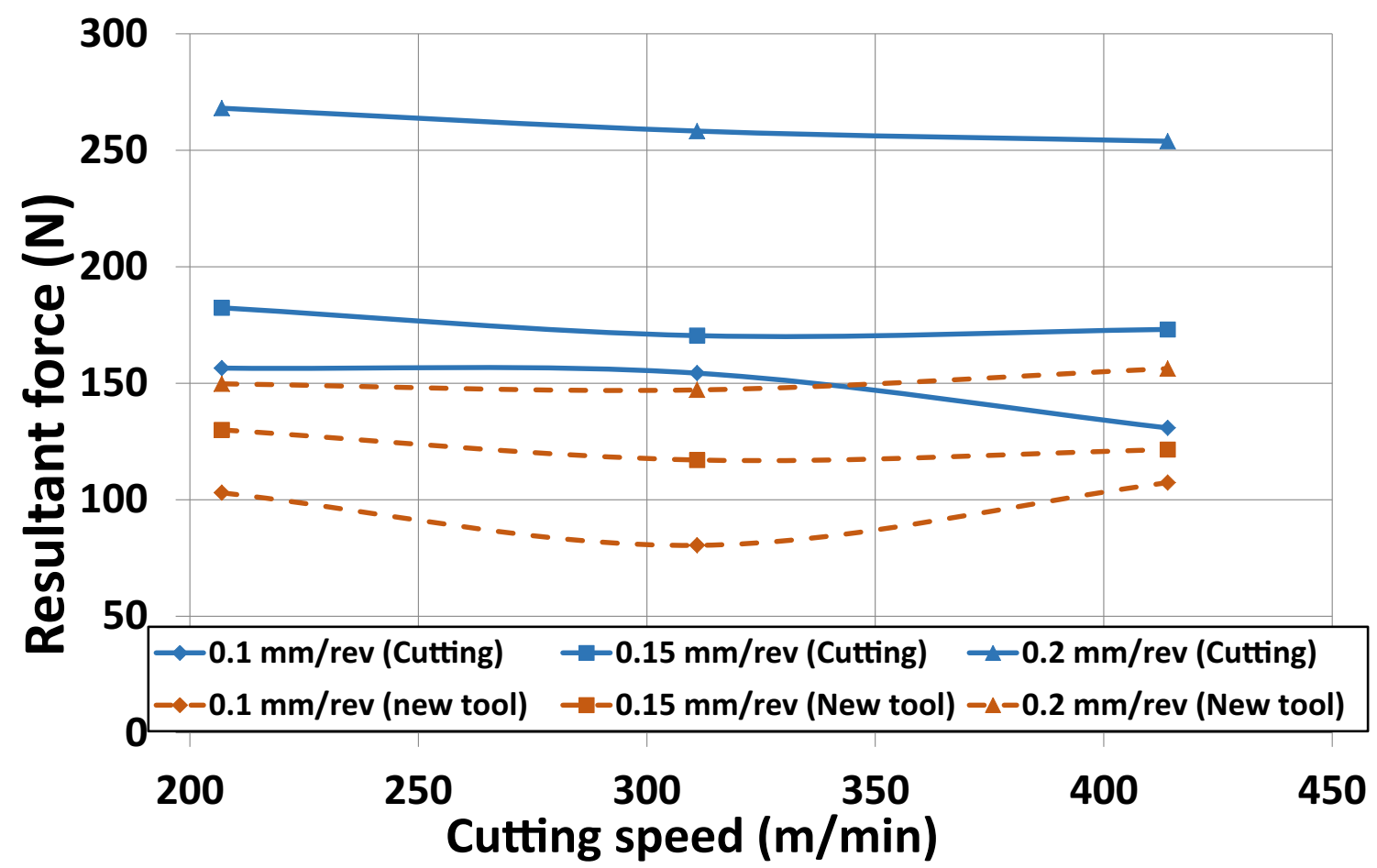

Fig. 11 Resultant force vs cutting speed and feed rate at $0.5 \mathrm{~mm}$ depth of cut (Resultant force $=(\mathrm{F} 2 \mathrm{x}+\mathrm{F} 2 \mathrm{y}+\mathrm{F} 2 \mathrm{z}) 1 / 3$, where $F x=$ radial direction, $F y=$ cutting direction and $F z=$ feed direction)
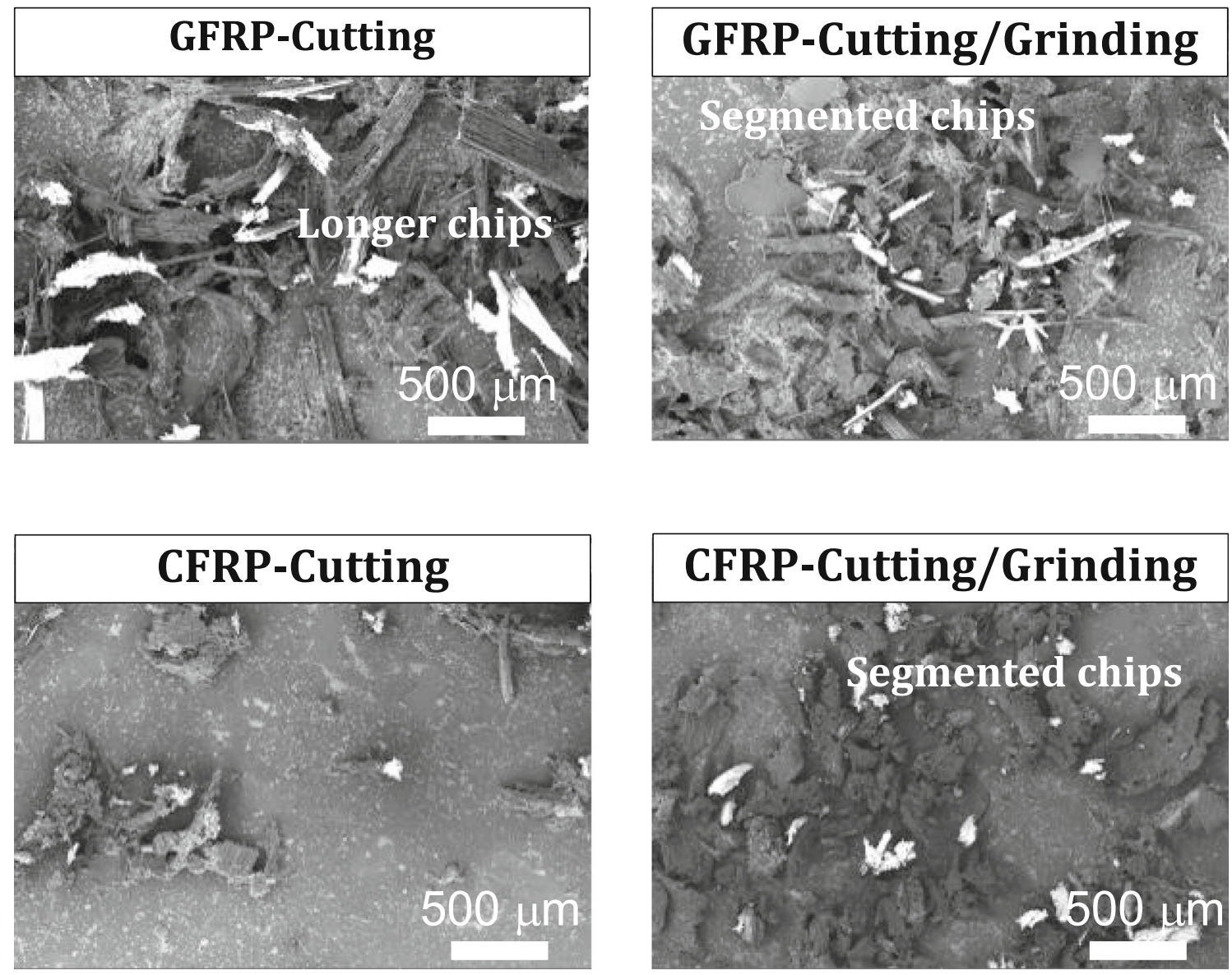

Fig. 12 Analysis of chip morphology 
with results from cutting-only research by Köpf et al. [18]. Although the radial force was in general lower with the new cutting-abrasive tool, it reduced at higher cutting speeds. Amongst the three force components, the radial force was the largest for all trials. This is attributed to the understandable spring-back of the composite machined surface, which pushes the tool in the radial direction.

Compared with cutting-only forces during the machining of CFRP, hybrid machining produced $F y$ and $F z$ forces which were marginally higher under the same operating conditions. However, radial forces were higher than when cutting-grinding, which is attributed to the higher spring-back of the machined surface in cutting-only mode. Additionally, the minimal end cutting edge angle $\left(0.5^{\circ}\right)$ used in the research resulted in larger contact with the machined surface. It led to instability of the cutting processes, evidenced by the large fluctuation of radial force during conventional cutting. However, in the case of cutting-grinding, less spring-back was generated and also the multiple cutting edges in the grinding zone acted to damp/ stabilize the process as evidenced by the stable radial force profile in the hybrid process.

\subsection{Chip morphology}

SEM examination of chip morphology revealed that the use of the new cutting-abrasive tools resulted in smaller/segmented chips; see Fig. 12. This could be ascribed to the presence of abrasive grits. This was clear in the case of CFRP tubes. Due to the improvement achieved in surface quality when the new cutting-grinding tools were used as well as high levels of material removal rates (by ensuring cutting remains active), the new tools eliminate the need for additional finishing processes and all subsequent secondary operations (setup, tool changing, etc.), which is anticipated to result in an increased production rate.

\section{Conclusions}

In this paper, the performance of a new hybrid cutting-abrasive tool (turn-grind) is evaluated through machining experiments on fibre reinforced polymer (FRP) composites. The results show that improvement in terms of composite workpiece surface quality and lower overall resultant force was achieved using the new cutting-abrasive tool as compared with the cutting-only tool. A reduction in the resultant force of up to $50 \%$ was also achieved with the new cutting-abrasive tools. The highest reduction was recorded for the radial force component. Typical edge rounding of the diamond abrasive grits was the principal wear mode. Compared with cutting-only, measurement of surface roughness $(\mathrm{Ra})$ in the axial and radial directions surprisingly showed an increase for both CFRP and GFRP when using the new cutting-abrasive tool. Roundness error also reduced to $20 \%$ for
CFRP and $38 \%$ for GFRP with an average of around $50 \%$. Compared with cutting-only, finer grinding swarf was seen in the chips following the machining trials.

The hybrid tool developed in the current study opens the door for future explorations. Additional research would be carried out to investigate the application of the hybrid tool on other materials, conduct a thorough evaluation of the effect of cutting parameters on the quality of the machined parts and consequently optimize the parameters to obtain components with improved surface quality and geometrical accuracy for different applications. Further research might also be directed to apply the same technology using the new hybrid tool to more complex machining operations such as milling and drilling. Finally, the influence of tool material and tool geometry on tool performance, tool wear and chip formation mechanisms would also require further investigation.

Authors' contributions I.S., D.H., P.H., H.E. and M.A.E. contributed equally.

Funding The authors would like to acknowledge the support from Northumbria University Competing.

Data availability The datasets generated during and/or analysed during the current study are available from the corresponding author on reasonable request.

\section{Compliance with ethical standards}

Competing interests The authors declare no conflict of interest.

Ethical approval This chapter does not contain any studies with human participants or animals performed by any of the authors.

Consent to participate Not applicable for that section.

Consent to publish All authors have read and agreed to the published version of the manuscript.

Open Access This article is licensed under a Creative Commons Attribution 4.0 International License, which permits use, sharing, adaptation, distribution and reproduction in any medium or format, as long as you give appropriate credit to the original author(s) and the source, provide a link to the Creative Commons licence, and indicate if changes were made. The images or other third party material in this article are included in the article's Creative Commons licence, unless indicated otherwise in a credit line to the material. If material is not included in the article's Creative Commons licence and your intended use is not permitted by statutory regulation or exceeds the permitted use, you will need to obtain permission directly from the copyright holder. To view a copy of this licence, visit http://creativecommons.org/licenses/by/4.0/.

\section{References}

1. Shyha IS, Soo SL, Aspinwall DK, Bradley S (2011) The effect of peel ply layer on hole integrity when drilling carbon fibre- 
reinforced plastic. Proc Inst Mech Eng B J Eng Manuf 225(7): $1217-1223$

2. Teng X, Huo D, Shyha I, Chen W, Wong E (2018) An experimental study on tool wear behaviour in micro milling of nano $\mathrm{mg} / \mathrm{Ti}$ metal matrix composites. Int J Adv Manuf Technol 96(5):2127-2140

3. Teng X, Chen W, Huo D, Shyha I, Lin C (2018) Comparison of cutting mechanism when machining micro and nano-particles reinforced SiC/Al metal matrix composites. Compos Struct 203:636647

4. Teng X, Huo D, Chen W, Wong E, Zheng L, Shyha I (2018) Finite element modelling on cutting mechanism of nano $\mathrm{mg} / \mathrm{SiC}$ metal matrix composites considering cutting edge radius. J Manuf Process 32:116-126

5. Kahwash F, Shyha I, Maheri A (2015) Machining unidirectional composites using single-point tools: analysis of cutting forces, chip formation and surface integrity. Procedia Eng 132:569-576

6. Lauwers B, Klocke F, Klink A, Tekkaya AE, Neugebauer R, McIntosh D (2014) Hybrid processes in manufacturing. CIRP Ann 63(2):561-583

7. Li CP, Kim M-Y, Islam MM, Ko TJ (2016) Mechanism analysis of hybrid machining process comprising EDM and end milling. $\mathrm{J}$ Mater Process Technol 237:309-319

8. Celaya A, Lopez LN (2010) de Lacalle, F.J. Campa, and A. Lamikiz, ultrasonic assisted turning of mild steels. Int J Mater Prod Technol 37(1-2):60-70

9. Zhong Z, Lin G (2006) Ultrasonic assisted turning of an aluminium-based metal matrix composite reinforced with SiC particles. Int J Adv Manuf Technol 27(11-12):1077-1081

10. Ning F, Cong W, Pei Z, Treadwell C (2016) Rotary ultrasonic machining of CFRP: a comparison with grinding. Ultrasonics 66: $125-132$
11. Hu NS, Zhang LC (2004) Some observations in grinding unidirectional carbon fibre-reinforced plastics. J Mater Process Technol 152(3):333-338

12. Quan Y, Zhong W (2009) Investigation on drilling-grinding of CFRP. Front Mech Eng China 4(1):60-63

13. Soo SL, Shyha IS, Barnett T, Aspinwall DK, Sim W-M (2012) Grinding performance and workpiece integrity when superabrasive edge routing carbon fibre reinforced plastic (CFRP) composites. CIRP Ann 61(1):295-298

14. Boudelier A, Ritou M, Garnier S, Furet B (2011) Optimization of process parameters in CFRP machining with diamond abrasive cutters. Adv Mater Res 223:774-783

15. Sheikh-Ahmad JY (2009) Machining of polymer composites. Springer, New York. https://doi.org/10.1007/978-0-387-68619-6

16. Awaja F, Pigram PJ (2009) Surface molecular characterisation of different epoxy resin composites subjected to UV accelerated degradation using XPS and ToF-SIMS. Polym Degrad Stab 94(4):651658

17. Ruszaj A, Skoczypiec S, Wyszyński D (2017) Recent developments in abrasive hybrid manufacturing processes. Manag Prod Eng Rev 8(2):81-90. https://doi.org/10.1515/mper-2017-0020

18. Köpf A, Feistritzer S, Udier K (2006) Diamond coated cutting tools for machining of non-ferrous metals and fibre reinforced polymers. Int J Refract Met Hard Mater 24(5):354-359

Publisher's note Springer Nature remains neutral with regard to jurisdictional claims in published maps and institutional affiliations. 